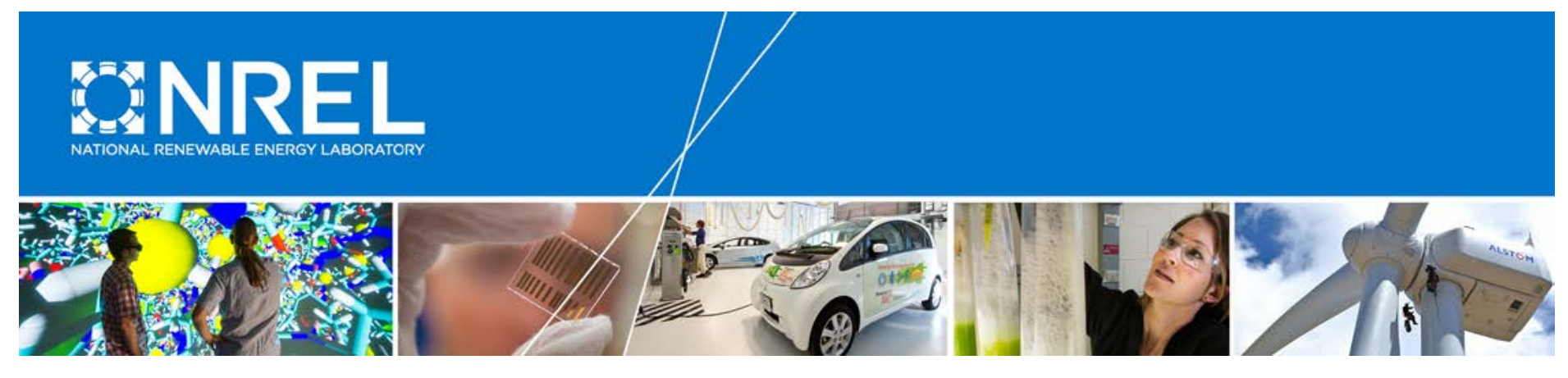

\title{
Evaluation of Performance and Opportunities for Improvements in Automotive Power Electronics Systems
}

\section{Preprint}

Gilberto Moreno, Kevin Bennion, Charles King, and Sreekant Narumanchi National Renewable Energy Laboratory

Presented at ITHERM 2016 - The 15th IEEE Intersociety Conference on Thermal and Thermomechanical Phenomena in Electronic Systems

Las Vegas, Nevada

May 31 - June 3, 2016

NREL is a national laboratory of the U.S. Department of Energy Office of Energy Efficiency \& Renewable Energy Operated by the Alliance for Sustainable Energy, LLC

This report is available at no cost from the National Renewable Energy Laboratory (NREL) at www.nrel.gov/publications.

Conference Paper

NREL/CP-5400-65672

June 2016 


\section{NOTICE}

The submitted manuscript has been offered by an employee of the Alliance for Sustainable Energy, LLC (Alliance), a contractor of the US Government under Contract No. DE-AC36-08GO28308. Accordingly, the US Government and Alliance retain a nonexclusive royalty-free license to publish or reproduce the published form of this contribution, or allow others to do so, for US Government purposes.

This report was prepared as an account of work sponsored by an agency of the United States government. Neither the United States government nor any agency thereof, nor any of their employees, makes any warranty, express or implied, or assumes any legal liability or responsibility for the accuracy, completeness, or usefulness of any information, apparatus, product, or process disclosed, or represents that its use would not infringe privately owned rights. Reference herein to any specific commercial product, process, or service by trade name, trademark, manufacturer, or otherwise does not necessarily constitute or imply its endorsement, recommendation, or favoring by the United States government or any agency thereof. The views and opinions of authors expressed herein do not necessarily state or reflect those of the United States government or any agency thereof.

This report is available at no cost from the National Renewable Energy Laboratory (NREL) at www.nrel.gov/publications.

Available electronically at SciTech Connect http:/www.osti.gov/scitech

Available for a processing fee to U.S. Department of Energy and its contractors, in paper, from:

U.S. Department of Energy

Office of Scientific and Technical Information

P.O. Box 62

Oak Ridge, TN 37831-0062

OSTI http://www.osti.gov

Phone: 865.576.8401

Fax: 865.576.5728

Email: reports@osti.gov

Available for sale to the public, in paper, from:

U.S. Department of Commerce

National Technical Information Service

5301 Shawnee Road

Alexandria, VA 22312

NTIS http://www.ntis.gov

Phone: 800.553 .6847 or 703.605 .6000

Fax: 703.605.6900

Email: orders@ntis.gov 


\title{
Evaluation of Performance and Opportunities for Improvements in Automotive Power Electronics Systems
}

\author{
Gilberto Moreno', Kevin Bennion, Charles King, Sreekant Narumanchi \\ National Renewable Energy Laboratory \\ 15013 Denver West Parkway \\ Golden, CO, USA, 80401 \\ ${ }^{1}$ Email: gilbert.moreno@,nrel.gov
}

\begin{abstract}
Thermal management strategies for automotive power electronic systems have evolved over time to reduce system cost and to improve reliability and thermal performance. In this study, we characterized the power electronic thermal management systems of two electric-drive vehicles - the 2012 Nissan LEAF and 2014 Honda Accord Hybrid. Tests were conducted to measure the insulated-gate bipolar transistor-tocoolant thermal resistances for both steady-state and transient conditions at various coolant flow rates. Water-ethylene glycol at a temperature of $65^{\circ} \mathrm{C}$ was used as the coolant for these experiments. Computational fluid dynamics and finite element analysis models of the vehicle's power electronics thermal management system were then created and validated using experimentally obtained results. Results indicate that the Accord module provides lower steady-state thermal resistance as compared with the LEAF module. However, the LEAF design may provide improved performance in transient conditions and may have cost benefits.
\end{abstract}

KEY WORDS: automotive, inverter, power electronics, thermal management

\section{NOMENCLATURE}

$\begin{array}{ll}\text { A } & \text { area } \\ \text { CFD } & \text { computational fluid dynamics } \\ \text { DBA } & \text { direct-bond aluminum } \\ \text { DBC } & \text { direct-bond copper } \\ \text { FEA } & \text { finite element analysis } \\ \text { IGBT } & \text { insulated-gate bipolar transistors } \\ \mathrm{k} & \text { thermal conductivity } \\ \mathrm{lpm} & \text { liters per minute } \\ \mathrm{Q} & \text { heat } \\ \mathrm{R}_{\text {th }} & \text { specific thermal resistance } \\ \mathrm{R}_{\text {th }} & \text { thermal resistance } \\ \mathrm{T} & \text { temperature } \\ \mathrm{T} 3 \mathrm{ster} & \text { transient thermal tester } \\ \mathrm{TIM} & \text { thermal interface material } \\ \mathrm{WEG} & \text { water-ethylene glycol } \\ \mathrm{Z}^{\prime \prime} & \text { specific thermal impedance }\end{array}$

\section{Subscripts}

$\begin{array}{ll}b & \text { baseplate } \\ c & \text { cold plate } \\ f & \text { fluid } \\ j & \text { junction } \\ t & \text { time }\end{array}$

\section{INTRODUCTION}

The trend towards vehicle electrification continues to increase in an attempt to develop more energy-efficient modes of transportation. A wide variety of electric-drive vehicles, including all electric, hybrid electric, and fuel cell vehicles, are currently available in the marketplace, and their numbers are expected to increase in future years. Power electronics are critical components found in all electric-drive vehicles. Ensuring reliable power electronics operation requires an effective and reliable thermal management strategy.

Traditional automotive power electronics power modules consist of IGBT soldered to DBC or DBA ceramic substrates. The ceramic substrates provide electrical isolation, but can also increase the thermal resistance due to their relatively low thermal conductivity. To improve thermal performance, some manufacturers move the electrical isolation and low-thermally conductive material farther away from the devices (e.g., IGBTs and diodes) to improve heat spreading. The 2006 Honda Civic Hybrid eliminates the DBA used in the prior design and instead solders the devices to a carbon-copper composite material [1]. A silicon nitride ceramic sheet placed between the carbon-copper composite and the copper baseplate is used to provide electrical insulation. The design is reported to reduce transient and steady-state thermal resistance as compared to the original DBA-based design. The 2008 Lexus LS600h Hybrid also eliminates the use of DBA or DBC substrates and utilizes double-sided cooling of the power modules to improve thermal management [2]. The cooling system uses a heat exchanger design with multiple cold plates. The heat exchanger is flexible and allows the coolant channels to be pressed against the power modules to improve thermal performance. The novel power module and cooling designs enable increased power density and are also used in the more recent 2013 Toyota Camry Hybrid [3].

Bennion and Kelly [4] used the 2008 Lexus LS600h power module design to evaluate the effect of different cooling techniques on the module's thermal performance. Their results indicate that using a more aggressive convective cooling technique may not provide a significant total thermal resistance reduction because of the passive stack resistance (i.e., conduction resistance) in the modules. Bennion and Moreno [5] used finite element modeling to compare the thermal performance of various power module designs across a wide range of convective heat transfer coefficient values. The results demonstrate the need to match the convective cooling performance to the power module design. In many cases, using a highly effective convective cooling technology may not have a significant effect on reducing the module's overall thermal resistance due to the relatively large passivestack thermal resistance. 
In this study, we characterized the power electronics thermal management systems for two new automotive systems - the 2012 Nissan LEAF and the 2014 Honda Accord Hybrid. Experimental testing of the hardware was first completed to measure the thermal resistance values of the systems. The laboratory tests were intended to provide an accurate means of measuring the thermal performance of the systems and were not intended to simulate actual automotive operating conditions. Steady-state and transient models were then created and validated. The thermal models were used to further understand the heat flow through the systems.

\section{EXPERIMENTAL PROCEDURES AND MODELING APPROACH}

Experiments were conducted to measure the junction-tocoolant resistance for the power electronics systems. A T3ster system was used to power and measure the temperature of the IGBT under test. For all tests, only one IGBT was powered to maximize the IGBT heat flux and temperature rise given the T3ster power supply limitations. Measuring IGBT temperatures required calibrating the voltage drop through the IGBT to its temperature. Calibration procedures involved attaching two calibrated K-type thermocouples to the power modules (thermocouples were placed near the IGBT that was to be tested). The inverters were then placed within a temperature-controlled chamber to obtain the voltage versus temperature calibration curves. During calibration and tests, a 1-milliamp sense current was passed through the IGBT to obtain a voltage drop, and a 10 -volt signal was used to gate the IGBT.

Once calibrated, the power electronics systems were connected to the WEG test bench. The test bench circulated WEG ( $50 \% / 50 \%$ of water and ethylene glycol by volume) at a $65^{\circ} \mathrm{C}$ inlet temperature through the systems' cold plates at various flow rates. The entire systems were insulated with thick layers of insulation to minimize thermal losses to the surrounding environment. The T3ster provided $60 \mathrm{~W}$ to 180 $\mathrm{W}$ of power to one IGBT under test. The amount of power varied according to the coolant flow rate (e.g., lower heat at low flow rates). During each test, the IGBT was powered for 15 minutes to allow for temperature equilibrium. After the IGBT reached steady-state conditions, power was removed and the temperatures were measured at 1-microsecond increments using the T3ster system. Steady-state temperatures were then calculated by extrapolating the temperature versus time results back to the time right before the power was shut down. The tests were repeated to ensure repeatable results.

The junction temperature was then used to compute the junction-to-liquid thermal resistance per Equation 1.

$$
R^{\prime \prime h, j-l}=\frac{\left(T_{j}-\overline{T_{f}}\right)}{Q_{I G B T}} \times A_{I G B T}
$$

where $T_{j}$ is the junction temperature, $\overline{T_{f}}$ is the average of the WEG inlet and outlet temperatures, $Q_{I G B T}$ is the total heat dissipated through the IGBT, and $A_{I G B T}$ is the area of the IGBT.

The laboratory tests were intended to provide an accurate means of measuring thermal resistance of power electronics systems and were not intended to simulate automotive operating conditions or environments. The experimental results were used to validate thermal models. The models were then to be used to understand the thermal performance of the systems under various conditions.

CFD and FEA were used to model the power electronics thermal management systems to better understand the heat flow through the components. CFD simulations were used to compute average heat transfer coefficients within the cold plates at various WEG flow rates. The computed heat transfer coefficient values were imposed as boundary conditions in the FEA models. The experimental results were used to validate the models. Once the models were validated, the models were used to predict steady-state and transient thermal resistance values under various conditions. The transient thermal resistance or thermal impedance $\left(Z{ }^{\prime}{ }_{t h}\right)$ was computed from modeling results using Equation 2.

$$
Z_{t h, j-f}(t)=\frac{T_{j, \max }(t)-T_{f}}{Q_{I G B T}} A_{I G B T}
$$

where $T_{j, \max }(\mathrm{t})$ is the maximum junction temperature, $T_{f}$ is the WEG temperature, $Q_{I G B T}$ is the total heat dissipated through the IGBT, $A_{I G B T}$ is the area of the IGBT, and $t$ is time.

\section{SYSTEM DESCRIPTION}

Images of the 2012 Nissan LEAF power electronics are shown in Fig. 1. The LEAF power electronics system (one inverter) controls and powers an $80-\mathrm{kW}$ (maximum power) permanent magnet machine and consists of various electronic components (e.g., capacitors, electrical boards, sensors, and interconnects) and three power modules that are attached onto a cast-aluminum cold plate [6]. The cold plate provides cooling for the power modules and is made up of a series of serpentine-finned channels through which the WEG coolant is circulated. The power modules consist of three IGBT-diode pairs per switch position. The schematic in Fig. 2 shows the various power modules layers from the IGBT to the cold plate. Unlike most power modules, the LEAF module does not use metalized-ceramic substrates (e.g., DBC substrates) for electrical isolation. Instead, the LEAF modules incorporate a flexible dielectric pad mounted between the power modules and the cold plate for electrical isolation (Fig. 1). TIM is applied on both sides of the dielectric pad to reduce thermal contact resistance.

Images of the 2014 Honda Accord power electronics system are provided in Fig. 3. The Accord power electronics system consists of two inverters for the two electric machines (motor and generator) found in the vehicle and one DC-to-DC boost converter. The Accord inverter does not use a "brick" style power module design, but instead uses a number of IGBTs and diodes soldered onto a DBC substrate to create the two inverters and boost converter. The same size (footprint) IGBTs and diodes are used throughout the entire system [7]. Fig. 4 shows the various layers (thermal path) of the Accord. As shown in Fig. 3, intricate finned structures are fabricated on the cold plate surface to augment cooling. Unlike the 2012 LEAF, the Accord does not utilize grease as a TIM between the layers. 


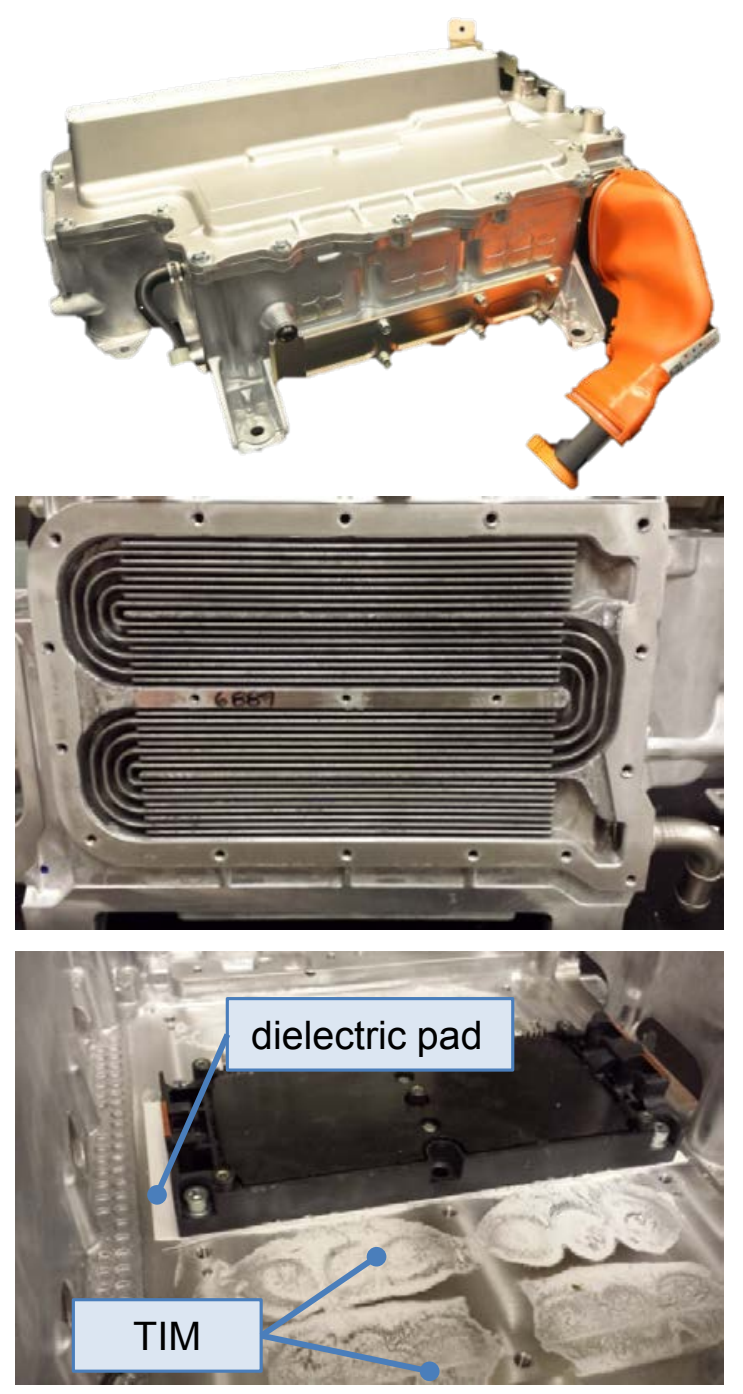

Fig. 1. Pictures of the 2012 Nissan LEAF power electronics system. The middle image shows the cold plate cooling channels. The lower image shows one power module attached to the cold plate. The dielectric pad and TIM layers are shown. Photo Credit: Gilberto Moreno (NREL)

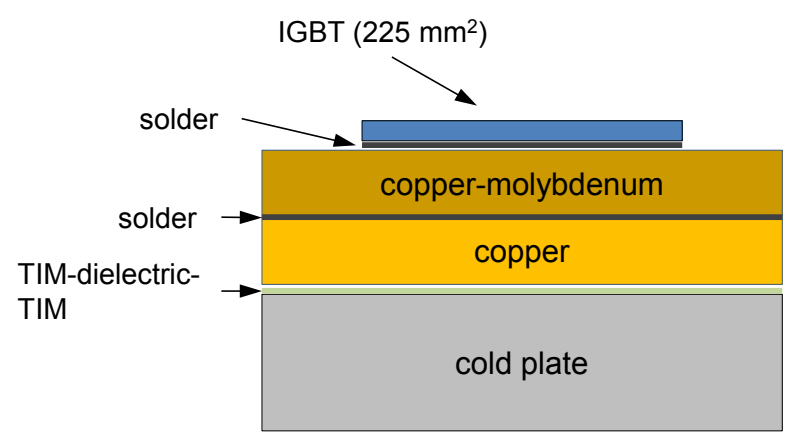

Fig. 2. Schematics showing the various layers of the 2012 LEAF power modules. The cold plate finned structures are not shown. Drawing not to scale.
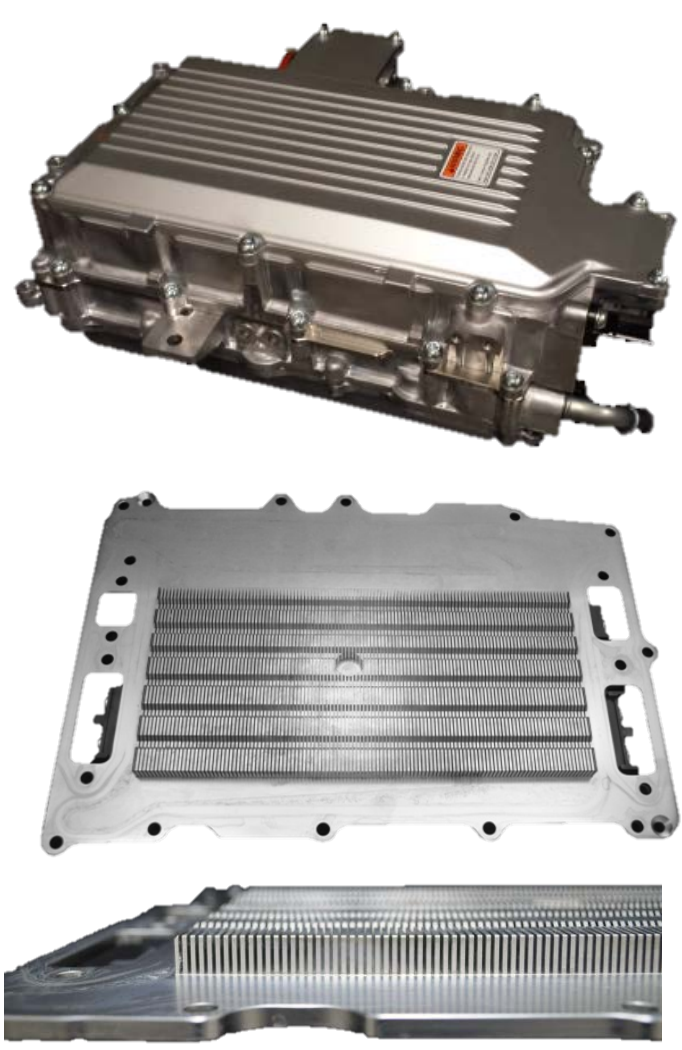

Fig. 3. Pictures of the 2014 Honda Accord power electronics system. The lower images show the cold plate finned structures. Photo Credit: Gilberto Moreno (NREL)

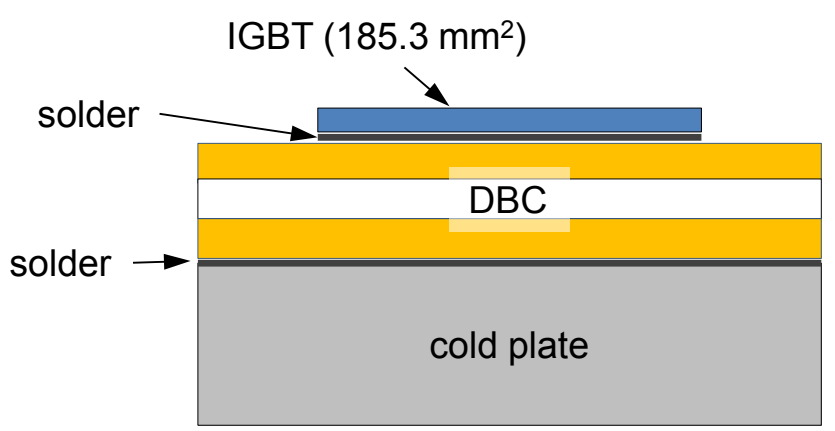

Fig. 4. Schematic showing the various layers of the 2014 Accord power modules. The cold plate finned structures are not shown. Drawing not to scale.

\section{RESULTS}

Experiments were conducted to measure the thermal resistance of the 2012 Nissan LEAF and 2014 Honda Accord power electronics systems. The experimentally measured junction-to-coolant specific thermal resistance values for the 2012 LEAF are provided in Fig. 5. The specific thermal resistance was defined in Equation 1. Measurements were taken at WEG flow rates ranging from $2 \mathrm{lpm}$ to $12 \mathrm{lpm}$ using a WEG inlet temperature of $65^{\circ} \mathrm{C}$. At the typical automotive power electronic flow rates (approximately $10 \mathrm{lpm}$ ), the junction-to-coolant specific thermal resistance was measured to be about $79 \mathrm{~mm}^{2}-\mathrm{K} / \mathrm{W}$. The results in Fig. 5 show that varying the flow rate has minimal effect on the thermal 
resistance values. This behavior indicates that the passivestack thermal resistance (i.e., heat conduction resistance) is significantly larger than the convective resistance (at the flow rates tested). The two TIM layers used in the LEAF design are likely large contributors to the large passive-stack resistance.

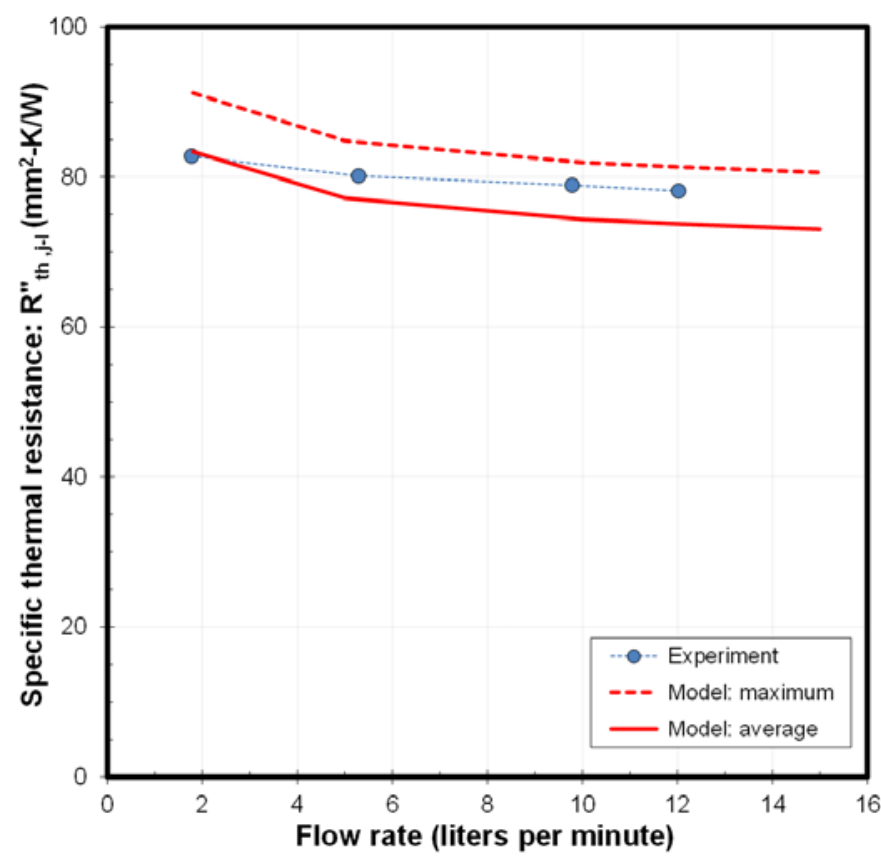

Fig. 5. Experimentally measured and model-predicted IGBT thermal resistance values for the 2012 Nissan LEAF power electronics system.

CFD and FEA thermal models were created to better understand the heat flow and to identify thermal bottlenecks in the system. The thermal models replicated the experimental conditions. Table 1 lists the power module material properties used in the models. Temperature-dependent thermal conductivity properties were used for silicon and copper [8]. The thermal conductivity of the dielectric pad was measured using the National Renewable Energy Laboratory's ASTM TIM stand. The composition (e.g., copper-molybdenum, solder) and thickness of some materials were selected so that the model results provided a good match with experimental data. The selected material property values were all within reasonable ranges.

CFD was used to compute average heat transfer coefficient values at the various WEG flow rates. The computed heat transfer coefficient values were then imposed as boundary conditions in an FEA model. The FEA model replicated the experimental conditions. Fig. 5 provides the model-estimated maximum (computed using the maximum junction temperature) and average (computed using the average junction temperature) thermal resistance values. As shown, the model-predicted results provide a good match with the experimental data (maximum approximately 6\% difference between the model and the experimental results).

The model was then used to generate a temperature profile from the IGBT to the coolant using $52.2 \mathrm{~W}$ of heat generated on the IGBT. The temperature profile is shown in Fig. 6. The results indicate that the passive-stack resistance provides about
$80 \%$ of the total temperature drop (junction-to-coolant). The TIM-dielectric pad-TIM interfaces are found to provide the largest resistance (accounts for $60 \%$ of the total temperature drop) within the passive stack. The use of the dielectric pad and two TIM layers obviously adds thermal resistance; however, the LEAF module design eliminates the metalized ceramic substrates typical of most power modules, and thus its design may offer cost and reliability advantages.

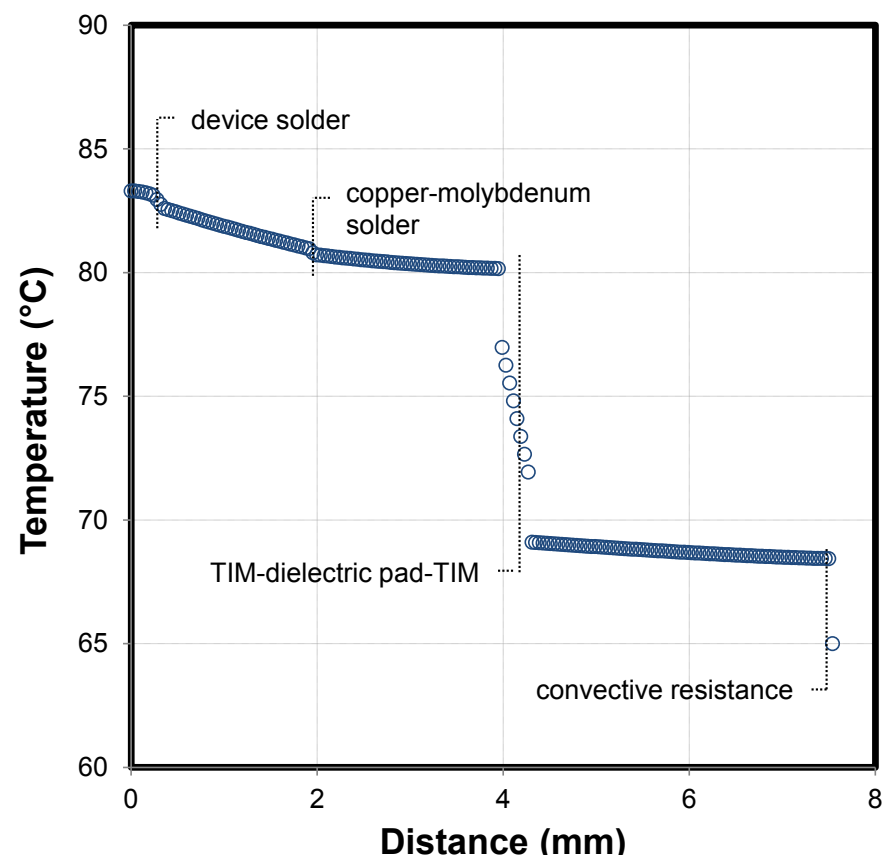

Fig. 6. Temperature profile through the 2012 LEAF power module depicting the thermal path from the IGBT to the coolant. The TIM-dielectric pad-TIM layers constitute a significant thermal resistance to the power modules.

Experiments were then conducted to measure the thermal performance of the 2014 Honda Accord power electronics system. Fig. 7 plots the junction-to-coolant specific thermal resistance values at various flow rates. Experiments were conducted at the same WEG flow rates and temperatures used for the LEAF experiments. The 2014 Accord system was found to provide thermal resistance values that were lower than the thermal resistance values provided by the 2012 LEAF inverter. At $10 \mathrm{lpm}$ the Accord provides a junction-to-coolant resistance of $44 \mathrm{~mm}^{2}-\mathrm{K} / \mathrm{W}$, which is about $44 \%$ lower than the 2012 LEAF resistance value measured at the same flow rate. The Accord's lack of TIM layers is the likely reason for its superior thermal performance. The lack of a TIM layer in the Accord reduces its passive-stack thermal resistance, which makes it more sensitive to increasing convective heat transfer (i.e., increasing flow rates) as compared with the LEAF.

FEA and CFD simulations were conducted to model the thermal performance of the 2014 Accord modules. Table 2 lists the thermal conductivity values used in the thermal models. CFD was used to compute the average cold plate heat transfer coefficients at various coolant flow rates $(2 \mathrm{lpm}-10$ $\mathrm{lpm}$ ) using a WEG inlet temperature of $65^{\circ} \mathrm{C}$. The computed heat transfer coefficients were then imposed on an FEA model. The model-predicted specific thermal resistance values 
are plotted in Fig. 7. Both the maximum (based on the maximum IGBT temperature) and average (based on the average IGBT temperature) specific thermal resistance values are provided. As shown, the model predicted values are found to match well with the experimental results. The FEA model results were then used to predict the temperature drop though the module from the IGBT to the coolant using $100 \mathrm{~W}$ of heat generated on the IGBT. As shown in Fig. 8, the silicon nitride layer is predicted to have the largest thermal resistance within the package.

Table 1. Thermal conductivity values used in the 2012 LEAF thermal models.

Thermal Conductivity

$(\mathrm{W} / \mathrm{m}-\mathrm{K})$

\begin{tabular}{|c|c|}
\hline Silicon & temperature dependent [8] \\
\hline $\begin{array}{l}\text { Copper-molybdenum } \\
(20 / 80)\end{array}$ & $164[9]$ \\
\hline Copper & temperature dependent [8] \\
\hline Dielectric pad & 2.6 \\
\hline Aluminum & $167[10]$ \\
\hline TIM & 1 \\
\hline Molding plastic & $0.34[11]$ \\
\hline
\end{tabular}

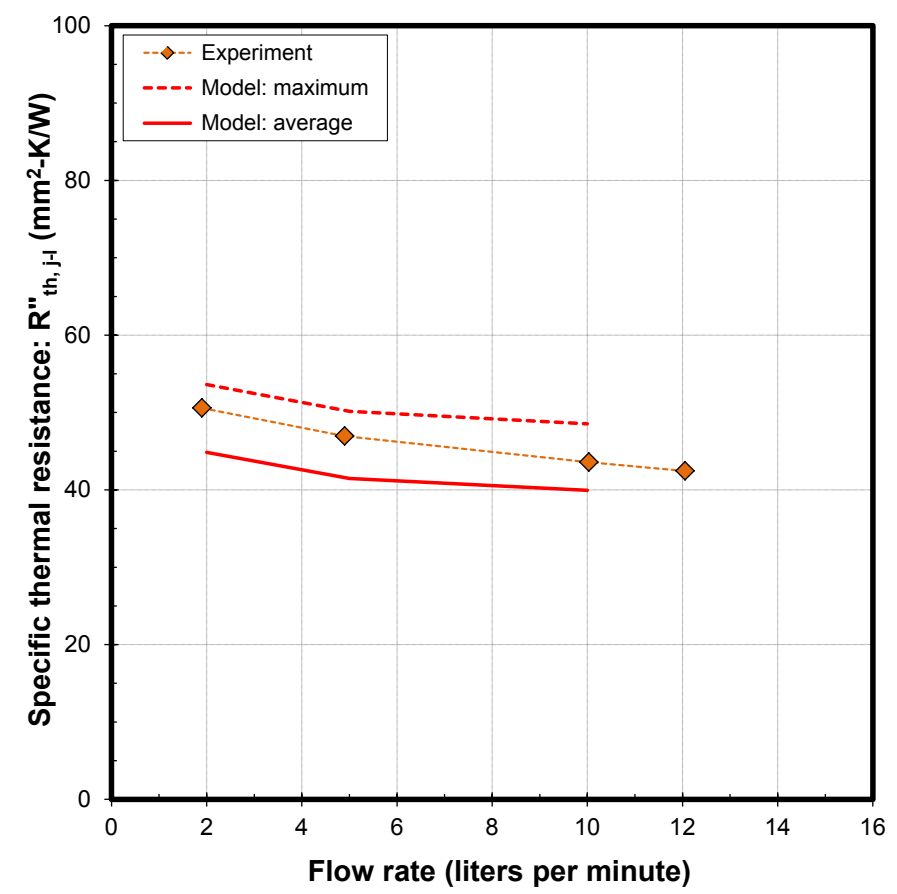

Fig. 7. Experimentally measured and model-predicted IGBT thermal resistance values for the 2014 Honda Accord power electronics system.
Table 2. Thermal conductivity values used in the 2014 Accord thermal models.

Thermal Conductivity

$(\mathrm{W} / \mathrm{m}-\mathrm{K})$

Silicon

temperature dependent

Copper

temperature dependent

Silicon Nitride

20 [12]

Aluminum

200 [13]

Molding plastic

0.34 [11]

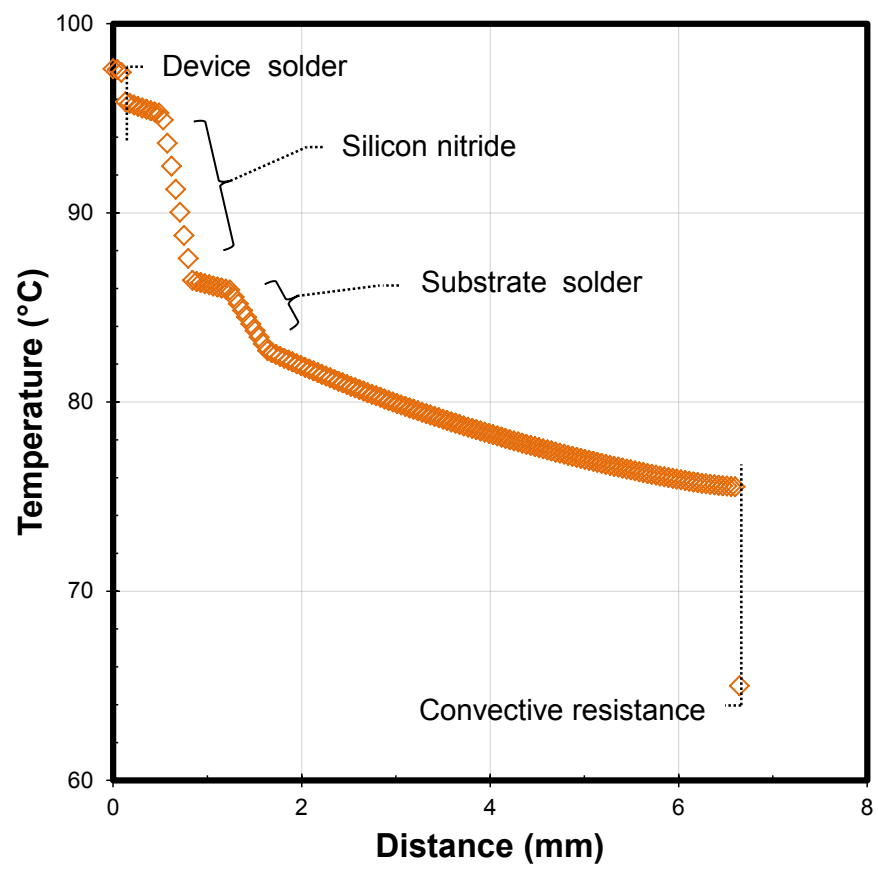

Fig. 8. Temperature profile through the 2014 Accord module depicting the thermal path from the IGBT to the coolant.

\section{Thermal Performance Comparisons}

FEA simulations were then conducted to compute and compare the steady-state thermal resistances of several power modules at a wide range of convective cooling thermal resistance values (i.e., convective heat transfer coefficient values). The LEAF and Accord power module performances were compared with the performance of a more conventional module design (module that incorporates a metalized-ceramic substrate and uses a TIM layer between the module and an aluminum cold plate). Two conventional power module designs were evaluated. One such design was created by modifying the LEAF module to eliminate the coppermolybdenum plates and dielectric pad and incorporate a DBC substrate. The DBC substrate consisted of a $0.38-\mathrm{mm}$-thick alumina sheet with two 0.25 -mm-thick copper layers on both sides. Alumina ceramic was chosen here because it is a 
material commonly used in module DBCs. A schematic of the modified LEAF module that incorporates a DBC substrate is shown in Fig. 9. The second conventional design was a Semikron SKM power module that incorporates an alumina DBC substrate. Both the DBC-modified LEAF and the Semikron modules include a TIM layer between the modules and an aluminum cold plate.

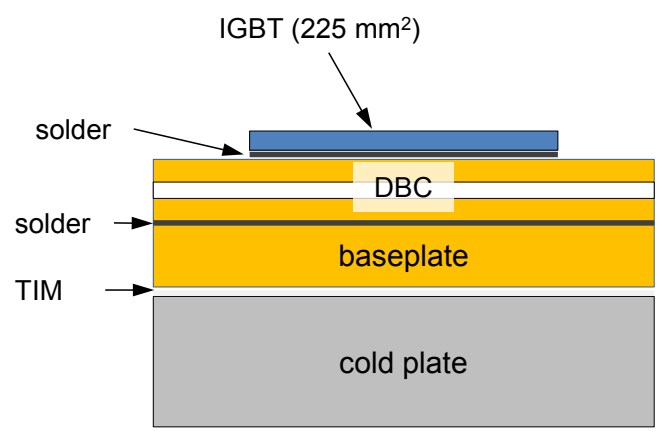

Fig. 9. Schematic showing the LEAF power configuration that incorporates a DBC substrate. Drawing not to scale.

Unlike the prior modeling results shown in Figures 5-8, these simulations were conducted by modeling heat generated on the entire power module (i.e., half-bridge, multiple IGBTs and diodes). Only one power module was modeled, and a three-to-one (IGBT-to-diode) heat loss ratio was used in the simulations. The Accord's power electronics do not use bricktype module design; therefore, one half-bridge segment from the motor's inverter that consisted of two IGBT-diode pairs per switch position was used for this study. The total power dissipated through the modules was adjusted so that the maximum junction temperatures reached $200^{\circ} \mathrm{C}$ at every convective thermal resistance condition. The $200^{\circ} \mathrm{C}$ junction temperature condition is high for typical silicon-based devices; however, this temperature condition was used in this study to simulate the effects of high temperature, wide-bandgap based devices. A $70^{\circ} \mathrm{C}$ temperature was used for the fluid temperature. In these analyses, the finned structures on the cold plate surface were not modeled, and the convective thermal resistance was imposed as a heat transfer coefficient boundary condition on the aluminum cold plate lower surface.

Fig. 10 provides the total thermal resistance versus the convective thermal resistance for the standard LEAF module, the LEAF module with the DBC configuration, the Accord module, and a Semikron SKM module. The total specific thermal resistance was defined per Equation 1 using the maximum junction temperature for $T_{j}$. As shown in Fig. 10, the specific thermal resistance for the LEAF (standard) power module is greater than the specific thermal resistance for the DBC configuration module - approximately 30\% greater at $R^{\prime \prime}{ }_{t h, c-f}=100 \mathrm{~mm}^{2}-\mathrm{K} / \mathrm{W}$. At a convective thermal resistance value of $R^{\prime \prime}{ }_{t h, c-f}=100 \mathrm{~mm}^{2}-\mathrm{K} / \mathrm{W}$, the Accord module's thermal resistance is approximately $38 \%$ and $12 \%$ lower than the LEAF and DBC-modified LEAF designs, respectively. Moreover, the Accord module's specific thermal resistance decreases at a faster rate with decreasing convective thermal resistance values. This behavior indicates that the Accord's passive stack thermal resistance is lower as compared with the three other modules evaluated. It should be noted that the total cooled surface area (area where the convective boundary condition is applied) is different for the various module designs and is the smallest for the Accord module. Finally, the performance of the LEAF module with the DBC configuration is similar to the performance of the Semikron SKM module that also incorporates a DBC substrate, which helps to confirm the performance of a typical DBC-based power module.

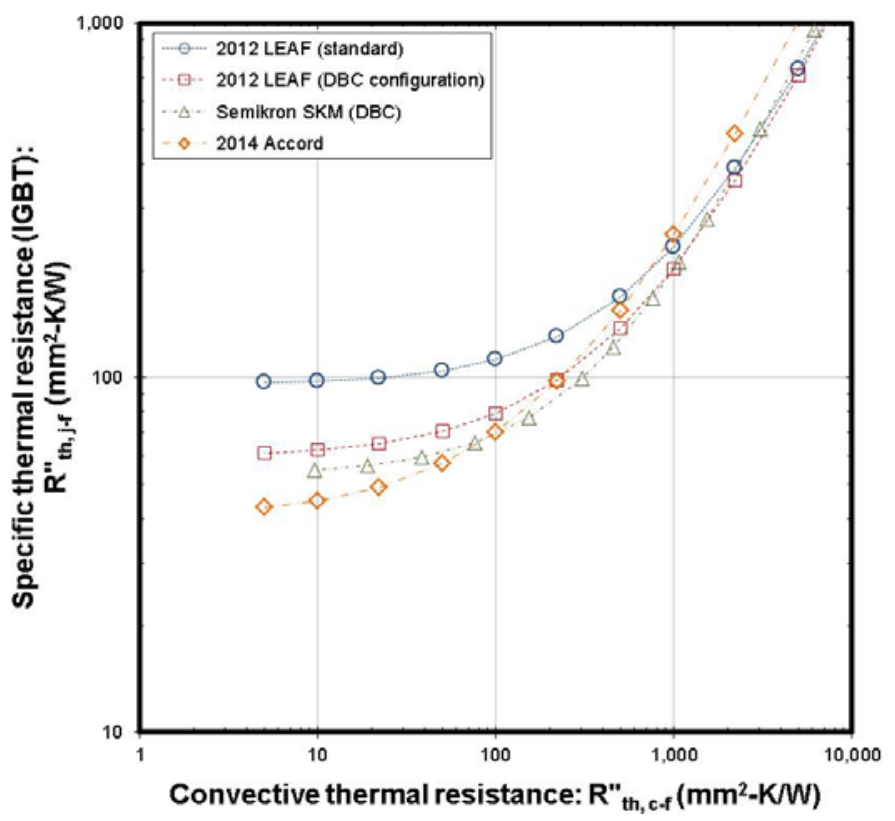

Fig. 10. Specific (junction-to-liquid) thermal resistance plotted versus the convective thermal resistance for the two LEAF module configurations, the 2014 Accord module, and a Semikron module. The Semikron SKM data were taken from Bennion and Moreno [5].

FEA simulations were also conducted to compare the transient thermal performance of three power modules. Fig. 11 plots the thermal impedance of the LEAF, LEAF with a DBC configuration, and Accord modules for the case when the modules are initially at a uniform temperature of $70^{\circ} \mathrm{C}$ and power to the devices was turned on (i.e., increasing temperature condition). The total heat imposed in the power modules was 2,084 W, 2,956 W, and 1,865 W for the LEAF, DBC-LEAF variant, and Accord, respectively. The total heat dissipated for each module differs because the heat was adjusted so that the maximum junction temperature reached $200^{\circ} \mathrm{C}$, and each module has a different junction-to-coolant thermal resistance. Although the Accord has the lowest thermal resistance, it also has fewer IGBTs as compared with the LEAF design, and thus it dissipated the least amount of heat (in this analysis). A three-to-one (IGBT-to-diode) heat loss ratio and a convective thermal resistance of $100 \mathrm{~mm}^{2}$ $\mathrm{K} / \mathrm{W}$ with a fluid temperature of $70^{\circ} \mathrm{C}$ were used for transient simulations.

The thermal impedance for the LEAF (standard) module was found to be lower than the thermal impedance (about $25 \%$ lower than the Accord at 100 milliseconds) for the Accord module and LEAF module with the DBC configuration at time scales below one second. Lower thermal impedance for the 
standard LEAF module at lower time scales is believed to be associated with the placement of a highly conductive copper molybdenum plate directly below the IGBT and moving the low-thermally conductive layer (i.e., dielectric pad) farther down the thermal path, which allows the heat to spread. In contrast, the DBC configuration modules have a relatively low-thermally conductive ceramic plate placed near the heat source, which limits the initial heat spreading. Additionally, the thermal mass of the relatively thick copper molybdenum plate increases the heat capacitance near the devices. At time scales greater than one second, the thermal impedance of the LEAF (standard) module becomes greater than the thermal impedance of the DBC-LEAF and Accord modules as conditions approach steady-state operation. These results suggest that there may be some transient benefits to the standard LEAF module design. As previously mentioned, the LEAF module may also offer cost and reliability advantages over the conventional metalized-ceramic substrate modules.

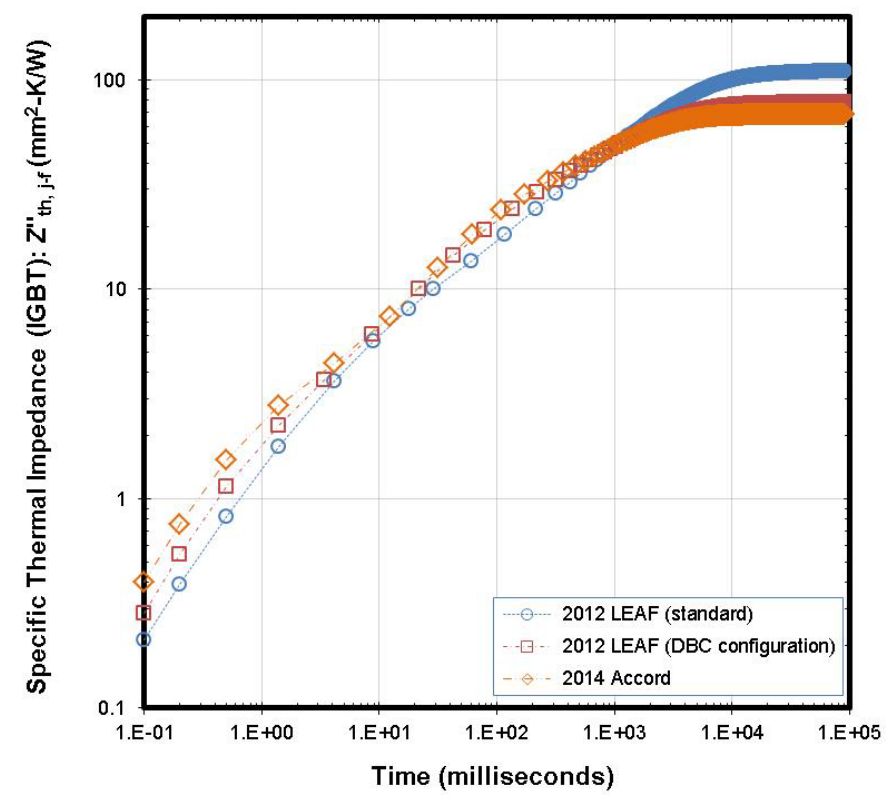

Fig. 11. Transient junction-to-liquid thermal impedance plotted versus time.

\section{SUMMARY AND CONCLUSIONS}

Experiments were conducted to characterize the thermal performance of the 2012 Nissan LEAF and 2014 Honda Accord Hybrid power electronics thermal management systems. CFD and FEA models were developed and validated using experimentally obtained results. The experimental and modeling data were then used to understand and compare the heat transfer within each system. The major conclusions from this study are summarized below.

- Results indicate that the LEAF power module has a higher steady-state total thermal resistance as compared with the 2014 Accord and more conventional module designs (modules that incorporates a metalized-ceramic substrate and use a TIM layer between the module and a cold plate). The LEAF's dielectric pad and associated TIM interfaces (on both sides of the dielectric pad) are the largest thermal resistance and account for approximately $60 \%$ of the total thermal resistance.

- The 2014 Accord Hybrid power electronics system was found to provide steady-state thermal resistance values that were about $44 \%$ lower than those of the 2012 LEAF when compared at a WEG flow rate of $10 \mathrm{lpm}$. The 2014 Accord system's lack of TIMs is a reason for its superior thermal performance. Modeling results indicate that the silicon nitride layer is the largest thermal resistance within the Accord's passive stack.

- Transient modeling results indicate that the 2012 LEAF power modules provide lower thermal impedance as compared to the Accord module at time scales less than one second. The LEAF's design which moves the lowthermally conductive materials (e.g., ceramics, dielectric pad) further down the thermal path allows heat to spread near the heat source. This heat-spreading effect combined with the thermal capacitance of the copper-molybdenum plate is believed to enable improved transient thermal performance for the LEAF modules. These results suggest that the LEAF power module may offer advantages under certain transient operating conditions.

\section{ACKNOWLEDGMENTS}

The author would like to acknowledge the support provided by Susan Rogers and Steven Boyd, Technology Development Managers for the Electric Drive Technologies Program, Vehicle Technologies Office, U.S. Department of Energy Office of Energy Efficiency and Renewable Energy. This work was supported by the U.S. Department of Energy under Contract No. DE-AC36-08GO28308 with the National Renewable Energy Laboratory. Funding was provided by U.S. DOE Office of Energy Efficiency and Renewable Energy Vehicle Technologies Office. The U.S. Government retains and the publisher, by accepting the article for publication, acknowledges that the U.S. Government retains a nonexclusive, paid-up, irrevocable, worldwide license to publish or reproduce the published form of this work, or allow others to do so, for U.S. Government purposes.

\section{REFERENCES}

[1] H. Ohtsuka and F. Anraku, "Development of inverter for 2006 model year Civic Hybrid," Power Convers. Conf. Nagoya, Japan, pp. 1596-1600, Apr. 2007.

[2] Y. Sakai, H. Ishiyama, and T. Kikuchi, "Power control unit for high power hybrid system," presented at the SAE International, 2007, pp. 25-29.

[3] T. Burress and S. Campbell, "Benchmarking EV and HEV power electronics and electric machines," Transp. Electrification Conf. Expo ITEC 2013 IEEE, pp. 1-6, Jun. 2013.

[4] K. Bennion and K. Kelly, "Rapid modeling of power electronics thermal management technologies," presented at the 5th IEEE Vehicle Power and Propulsion Conference, 2009.

[5] K. Bennion and G. Moreno, "Thermal management of power semiconductor packages-matching cooling technology with packaging technologies," presented at the 2nd Adv. Tech. Workshop on Automotive Microelectronics and Packaging, $2010,2010$. 
[6] Y. Sato, S. Ishikawa, T. Okubo, M. Abe, and K. Tamai, "Development of high response motor and inverter system for the Nissan LEAF electric vehicle," SAE Technical Paper, 2011.

[7] T. A. Burress, "Benchmarking EV and HEV

technologies," Oak Ridge National Laboratory, 2014 VTO

EDT Annual Report, 2014.

[8] J. H. Lau and Y. H. Pao, "Solder joint reliability of BGA, CSP, flip chip, and fine pitch SMT assemblies, 1997," NY

McGraw-Hill.

[9] Spectra-Mat, Inc. "Molybdenum-Copper Components" [Online]. Available: http://www.spectramat.com/pdf/PB-600D\%20Molybdenum\%20Copper\%20Components.pdf

[Accessed: 18-Mar-2016].

[10] MatWeb Material Property Data. "Aluminum 6061-T6; 6061-T651" [Online]. Available: http://www.matweb.com/search/datasheet.aspx?matguid=1b8c 06d0ca7c456694c7777d9e10be5b [Accessed: 18-Mar-2016].

[11] MatWeb Material Property Data. "Overview of Materials for Polyphenylene Sulfide (PPS)" [Online]. Available: http:/www.matweb.com/search/datasheet.aspx? matguid=301e 3f904d6a43a7922601c9d11ded91. [Accessed: 18-Mar-2016].

[12] MatWeb Material Property Data. "CeramTec SL200B Silicon Nitride" [Online]. Available: http://www.matweb.com/search/datasheet.aspx?matguid=50f7 07073d0149218469a887fb0bbf31 . [Accessed: 18-Mar-2016]. [13] MatWeb Material Property Data. “Aleris 55HX® Aluminum" [Online]. Available:

http://www.matweb.com/search/datasheet.aspx?matguid=b8de 580814574dda958c8b2a4aebe710. [Accessed: 18-Mar-2016]. 